\title{
BİST Sürdürülebilirlik Endeksinde Yer Alan Şirketlerin Kurumsal Sosyal Sorumluluk Faaliyetleri Üzerine Bir İçerik Analizi
}

\author{
DOI: $10.26466 /$ opus.583811
}

*

\section{Oğuzhan Aytar*}

*Dr. Öğr. Üyesi, Karamanoğlu Mehmetbey Üniversitesi, İ.̇̇.B.F., İşletme Böl., Karaman / Türkiye E-Posta: oguzhanaytar@hotmail.com

ORCID: 0000-0003-3799-0952

\section{Öz}

İ̧̧letmeler faaliyet yürüttükleri çevrede farkl paydaş ve paydaş gruplarıla etkileşim içindedir. Bu paydaş gruplarının her birinin işletmelerden bir takım beklentileri bulunmaktadır. Bu bağlamda kurumsal sosyal sorumluluk çalışmalarının paydaşların ortak beklentilerine ve memnuniyet düzeylerine yönelik olumlu yönde katkı sunduğu görülmektedir. İsletmelerin kurumsal sosyal sorumluluk stratejileri ve uygulamaları rekabet avantajı sağlama potansiyeline sahiptir. Borsa İstanbul (BIST) Sürdürülebilirlik Endeksi işletmelerin sosyal ve çevresel sorunların çözümüne yönelik sürdürülebilir politikalara önem verme düzeyini ölçmektedir. Bu açıdan BIST Sürdürülebilirlik Endeksi içinde yer alan örgütlerin sosyal sorumluluk çalışmaları önem arz etmektedir. Bu kapsamda çalı̧manın amacı BİST Sürdürülebilirlik Endeksinde yer alan işletmelerin kurumsal sosyal sorumluluk çalışmalarına yönelik bir içerik analizinin yapılmasıdır. Kurumsal sürdürülebilirlik performansları üst seviyede olan şirketlerin kurumsal sosyal sorumluluk çalşmaları rehber olarak kabul edilmektedir. Dolayısı ile şirketlerin kurumsal sosyal sorumluluk çalışmalarının içeriği ve sektörel açıdan farklılıkların ne yönde gelişme gösterdiği önem taşımaktadır. Çalışma sonucunda Sürdürülebilirlik Endeksi içindeki şirketlerin KSS faaliyetleri eğilimlerinin işletme ve sektör grupları açısından farklılık taşıdığ tespit edilmiştir.

Anahtar Kelimeler: Kurumsal Sosyal Sorumluluk, İçerik Analizi, BiST, Şirket 


\title{
A Content Analysis on Corporate Social Responsibility Activities of Companies in BIST Sustainability Index
}

\begin{abstract}
Businesses interact with different stakeholders and stakeholders groups in the environment in which they work. Each of these stakeholder groups has a number of expectations from businesses. In this context, it can be seen that corporate social responsibility activities contribute positively to the common expectations and satisfaction levels of the stakeholders. Corporate social responsibility strategies and practices of businesses have the potential to provide competitive advantage. Borsa Istanbul (BIST) Sustainability Index measures the level of giving importance to sustainable policies for the solution of social and environmental problems. From this point it is important that social responsibility activities of the organizations included in the BIST Sustainability Index. The purpose of this study conducting content analysis for corporate social responsibility activities of businesses in BIST Sustainability Index. Corporate social responsibility activities of companies with high level of corporate sustainability performance are considered as a guide. Therefore, the content of corporate social responsibility activities of companies and to see how the differences develop is important in terms of sectoral differences. In the result of the study, it was found that the CSR activities tendency of the companies in the Sustainability Index differed in terms of enterprise and sector groups.
\end{abstract}

Keywords: Corporate Social Responsibility, Context Analysis, BIST, Company. 


\section{Giriş}

Dünya genelinde örgüt faaliyetlerini kısıtlayan temel konulardan bir tanesi de kaynak kıtlığıdır. Tüketicilerin bilinçlenmesi ve kitle iletişim araçlarının boyut değiştirmesi bu kaynakların çok daha bilinçli kullanımını gerektirmektedir. Temel olarak kurumsal sosyal sorumluluk çalışmaları insanlar, gezegen ve kar üçlüsünün entegrasyonu adına kamu çıkarlarının bilinçli bir şekilde kurumsal karar alma sürecine dahil edilmesidir (Elmualim, 2017, s.1579). Günümüzde tüketiciler sadece ürünlerden elde ettikleri faydayı değil bu ürünlerin elde edilme sürecindeki örgüt davranışlarını da dikkate almaktadırlar. Özellikle paydaş oryantasyonunun daha yüksek olduğu ülkelerde çalışanlar, tüketiciler ve devlet gibi paydaşlar bir şirketin kurumsal sosyal sorumlulukları hakkında daha yüksek beklentiye ve rekabet avantajı açısından daha yüksek etki potansiyeline sahiptir (Cheung vd., 2018, s.507; Liao vd., 2018, s.362). Enerji verimliliği, yenilikçilik, etkinlik, geri dönüşüm imkanları ve atık yönetimi gibi konular dünya vatandaşlarının en güncel ve en ilkeli beklentileri bulunan konular içinde yer almaktadır. Dolayısıyla örgütlerin süreklilikleri için kendi ç1karları ile toplumsal çıkarları uyumlu bir düzlemde kaynaştırmayı; doğaya, topluma ve gelecek nesillere ait değerlere saygılı bir yaklaşım sergilemeyi gerektirmektedir (Can ve Özgül, 2018, s.8). Bu kapsamda işletmeler için kurumsal sosyal sorumluluk stratejileri ve uygulamaları, farkl1laşma sağlayarak rekabet avantajına dönüşme potansiyeline sahiptir (Kunz, 2018, s.30). Bu amaçla KSS faaliyetleri evrensel açıdan değerlendirilmelidir. Örgütler asli faaliyetlerini yürütürken toplumun ve dünya vatandaşlığının menfaatini de düşünmek durumundadırlar (Çelik, 2007, s.44).

Günümüzde örgütlerin açık sistem anlayışını kabul ederek paydaş beklentilerini ve hassasiyetlerini göz önünde bulundurmaları gerekmektedir. Örgütler kendi amaçlarını yerine getirirken, dış paydaş gruplarından toplum menfaatlerinin farklı boyutlarını ve etki alanlarını da belirlemeleri beklenmektedir. Kurumsal sosyal sorumluluk yaklaşımının evrensel nitelikleri farklı kültürler özelinde farklı yönetsel etkilere sahiptir (Paşamehmetoğlu ve Gökoğlu, 2019, s.126). Örneğin yapılan çalışmalar özelinde $A B D, A B$ ve Çin firmaları arasında kurumsal sosyal sorumluluğa yönelik anlamsal algı farklılığı bulunduğu; Asya, Avrupa, ABD \Kanada 
ve Çin firmaları arasında da KSS iletişimi açısından anlamlı farklılıkların bulunduğu görülmektedir (Liao vd., 2018, s.362; Liao vd., 2017, s.334-335; Benn ve Bolton, 2011, s.59).

Örgütlerin amaçlarına ulaşma yetkinliği ve başarısının sahip olunan insan kaynağının niteliğine bağlı olarak gerçekleştiği bilinmektedir. Nitelikli insan kaynağı beklentilerinin ise özellikle dış paydaşlar tarafından kabul görmüş, toplumsal sorumluluklarını yerine getiren saygın örgütler tarafından karşılandığı görülmektedir. Bu açıdan bakıldığında kurumsal sosyal sorumluluk uygulamalarının nitelikli eleman istihdamı üzerinde olumlu yönde etkili olduğu söylenebilir (Atay ve Tüzüner, 2018, s.283). İşletmeler kurumsal sosyal sorumluluk çalışmalarını sadece dış paydaşların beklentilerini karşılamak amacıyla değil, çalışanlar açısından da beklentileri karşılayan ve KSS kültürünün güçlenmesi amacıyla yapmaktadırlar (Elmas Atay ve Tüzüner, 2018, s.272). Sosyal sorumluluk bilincine sahip ve mensubu olduğu topluma duyarlı bir örgüt, güçlü bir sosyal sermaye geliştirmektedir. Bu özellik örgüte farkındalık kazandırmakla birlikte daha çok tercih edilmesini sağlamaktadır (Sarıkaya ve Akarca, 2011, s.61).

\section{Literatür Taraması}

Şirket grupları üzerinde kurumsal sosyal sorumluluk konusuyla ilişkili sınırlı sayıda çalışmanın bulunduğu görülmektedir. Bu çalışmalardan konumuz ile doğrudan ilgili olan bir kaç araştırma sonucu şu şekilde sıralanmaktadır :

- Paşamehmetoğlu ve Gökoğlu (2019) Türkiye'ye özgü kurumsal sosyal sorumluluk anlayışını ortaya koymak amacıyla evrensel KSS değerleri açısından otelcilik sektörünü incelemişlerdir. İçerik analizi yönteminin kullanıldığı çalışmada; yönetsel uygulamaların sosyal taleplere yönelik sosyal sorumluluk boyutunu daha fazla yansittı̆̆ görülmüştür.

- Can ve Özgül'ün (2018) yapmış olduğu araştırmada Fortune 500 Türkiye 2017 listesinde yer alan ihracatta ilk 100 içerisinde olan şirketler örneklem olarak kabul edilmiştir. Bu işletmelerin sürdürülebilirlik teması üzerine içerik analizi uygulanmıştır. Araştırmanın en önemli 
bulgularından birisi Türkiye'de kurumsal sürdürülebilirliğin raporlanmasına dair yeterli farkındalık düzeyinin henüz oluşmadığının tespit edilmesidir.

- Kunz (2018) çalışmasında Fortune 500 listesinde yer alan şirketlerin web sitelerinde yayınlanan kurumsal sosyal sorumluluk (KSS) bilgilerini ve yayınlanan resmi raporlarını analiz ederek, şirket büyüklüğü ve faaliyet bölgesinin raporlama formatı ve içeriği üzerinde etkili olduğu sonucuna varmıştır. Çalışmada sektör farklılığının raporlama üzerinde etkisine rastlanılmamıştır.

- Atay ve Tüzüner'in (2018) çalışmasında mevduat bankalarının kurumsal sosyal sorumluluk çalışmaları ile insan kaynakları uygulamalarının etkileşimi incelenmiş, kurumsal sosyal sorumluluk faaliyetlerine ilişkin bilgilendirmenin sürdürülebilirlik temasıyla daha yoğun bir etkileşim içinde olduğu görülmüştür.

- Gör ve Tekin'in (2018) Borsa İstanbul 100 Endeksinde yer alan şirketlerin kurumsal sosyal sorumluluk ve karlılık ilişkisinin incelendiği çalışmada kurumsal sosyal sorumluluk faaliyetlerinin karlılığa katkı yaptığı sonucuna ulaşılmıştır. Kurumsal sosyal sorumluluk faaliyetlerinin ticari örgütlerin aktif karlılığı ve özsermaye karlılı̆̆ üzerinde etkisi olduğu görülmektedir.

- Boz vd. (2019) yapmiş olduğu araştırmada Borsa İstanbul Kurumsal Yönetim Endeksinde yer alan işletmelerin kurumsal sosyal sorumluluk ve kurumsal yönetim puanları arasındaki etkileşimi verimlilik açısindan analiz edilmiştir.

- Özkan vd. (2018) çalışmalarında işletmelerin sürdürülebilirlik raporlarında yer alan kurumsal sosyal sorumluluk çalışmalarıyla finansal performans arasındaki ilişki incelenmiş, kurumsal sosyal sorumluluk açıklamalarının işletmelerin karlılık oranları üzerinde pozitif etkiye sahip olduğu tespit edilmiştir.

- Uluslararası ölçekte yapılan bazı araştırma (Liao vd., 2018; Liao vd., 2017) sonuçlarına göre firmaların KSS algısı ve KSS iletişiminde bölgesel açıdan anlamlı farklılıklar bulunduğu tespit edilmiştir. Yine Golob vd. (2018) çalışmalarında kurumsal sosyal sorumluluğun nasıl ölçüldüğü hakkında Türkiye ve Slovenya karşılaştırması yaparak bu iki toplumun kurumsal sosyal sorumluluk konusunda farklı bilişsel yapılara sahip olduklarını ortaya koymuşlardır. 


\section{Kurumsal Sosyal Sorumluluk}

Kurumsal sosyal sorumluluk formülasyonu II.Dünya Savaşı sonrasında ortaya çıkan bir konudur. İşletmelerin ticari faaliyetlerinden daha fazlasinı yapması ve yasalara koşulsuz uyması beklenen, dünya genelinde paydaşlar açısından yaşamsal öneme sahip modern bir dili ve yaklaşımı ifade etmektedir (Carroll, 2015, s.87). İşletmelerin yasalar ve ekonomik beklentiler dışında toplum çıkarına bir şeyler yapıyor olması kamuoyu tarafından işletmeye karşı olumlu tutumların gelişmesine destek olmaktadır (Fidan ve Şentürk, 2017, s.41).

Kurumsal sosyal sorumluluk örgütlerin ekonomik ve sosyal birimler olmalarından kaynaklanan ve yerine getirmekle sorumlu bulundukları faaliyetler bütünüdür (Sarıkaya ve Akarca, 2011, s.60). Bu faaliyetler yalnızca toplumun ihtiyaç duyduğu konularda çaba harcamak değil, şirketin sahip olduğu verileri doğru, şeffaf ve tarafsız olarak paylaşmasını ifade etmektedir. Bu paylaşım ilgililerin doğru ve güvenilir bilgilerle kararlarını etkileyerek şirket sürekliliğine katkı sunmaktadır (Özkan vd., 2018, s.573). Kurumsal sosyal sorumluluk kendi kendini düzenleme yeteneğine sahip işletmelerin mal ve hizmet üretme sürecinde tüm paydaşları dikkate alarak, şeffaf ve etik olmalarını ifade etmektedir (Elmualim, 2017: 1578; Suher, 2010, s.34).

Örgütler farklı amaçlar doğrultusunda uzmanlık alanlarıyla ilişkili maddi ve maddi olmayan sermaye unsurlarından oluşmaktadır. Bu sermaye unsurları örgütlerin asli faaliyetleri kapsamında anlam taşımaktadır. Örgütlerin özel amaçlarının yanı sıra toplumun ihtiyaç duyduğu genel amaçları da bulunmaktadır. Bu kapsamda yürütülmesi gereken bir takım faaliyetler doğrudan örgüt faaliyetleri içinde bulunmamasına rağmen örgüt sürekliliği açısından paydaşları hesaba katmak anlamında kritik önem taşımaktadır (Boz vd., 2019, s.120). Bu faaliyetler genel olarak kurumsal sosyal sorumluluk uygulamaları kapsamında değerlendirilmektedir.

İşletmelerde kurumsal sosyal sorumluluk çalışmaları toplumsal ihtiyaçların yanı sıra işletmelerin kendi gelecekleri için bir garanti primi olarak düşünülmeye başlanmıştır (Fidan ve Şentürk, 2017, s.41). İşletmelerde sadece kar odaklı yaklaşımların uzun vadede sürdürülebilirliği bulunmamaktadır (Özkan vd., 2018, s.572). Dolayısı ile süreklilikten sonra kar elde 
etme amacının değer maksimizasyonuna dönüşmesi, işletme paydaşlarının beklentilerini farklılaştırmaktadır. Günümüzde işletmelerin paydaşlarına yönelik değer yaratma çalışmalarının en işlevsel olanı kurumsal sosyal sorumluluk çalışmalarıdır. Kurumsal sosyal sorumluluk çalışmalarıyla işletmeler hem güçlü bir imaj ve itibar oluşturmakta hem de paydaşlarına fayda sağlamaktadır (Karadeniz ve Ünlübulduk, 2018, s.372; Önder, 2019, s.183).

Kurumsal sosyal sorumluluk sadece belirli paydaşları memnun edici kısa vadeli yaklaşımlar olarak görülmemelidir. Günümüzde kurumsal sosyal sorumluluk faaliyetleri örgütün sürekliliği kapsamında örgütün meşruiyetine olumlu katkıları bulunan zorunlu bir süreçtir (Golob vd., 2018, s.442; Sarıkaya ve Akarca, 2011, s.60).

Alan yazın içerisinde kurumsal sosyal sorumluluk kavramının tanımı üzerinde farklı görüşler bulunmaktadır. Literatürde en çok kabul gören kurumsal sosyal sorumluluk boyutları Carrol (1991) tarafindan ortaya konulmuştur. Bu boyutlar kurumsal sosyal sorumluluk piramidi olarak yapılan araştırmaların faaliyet çerçevesini oluşturmaktadır. Bu boyutlar ekonomik, yasal, etik ve gönüllü sorumluluk konu başliklarında incelenmektedir (Sarıkaya ve Akarca, 2011, s.61). Bu kapsamda genellikle kurumsal sosyal sorumluluk kavramının üç temel konu üzerine kurgulandığ1 görülmektedir. Bunlardan birincisi yasalara, ahlak ilkelerine, evrensel haklara ve çevresel duyarlılığa sahip olmayla ilişkili olduğu görülmektedir. İkinci konu paydaş beklenti ve menfaatlerinin göz önünde bulundurulmasıdır. Üçüncü ilke ise örgüt üst yönetiminin kurumsal sosyal sorumluluğa bakışı ve bu sorumluluğun kabulüyle ilişkilidir (Argüden, 2007, s.26).

\section{Çalışmanın Amacı ve Önemi}

Bu çalışmanın amacı BİST Sürdürülebilirlik Endeksinde yer alan işletmelerin kurumsal sosyal sorumluluk çalışmalarının incelenerek, önceden belirlenen temalar kapsamında içerik analizinin yapılmasıdır. Örneklem olarak BİST Sürdürülebilirlik Endeksi içinde yer alan örgütlerin seçilmesinin nedeni; sürdürülebilirlik endeksinin ideali arayan bir takım ölçüm kriterlerine sahip olması ve endeks içindeki şirketlerin kurumsal sosyal sorumluluk çalışmaları açısından belirli standartlara sahip olmalarıdır. Sürdü- 
rülebilirlik kavramının uygulamadaki somut çalışma alanını sosyal sorumluluk uygulamaları oluşturmaktadır. Dolayısı BİST Sürdürülebilirlik Endeksinde yer alan şirketlerin kurumsal sosyal sorumluluk çalışmalarının analizi çalışmanın çerçevesi açısından ideal özellikler taşımaktadır.

İşletmelerin faaliyette bulundukları sektör ve üyesi bulundukları topluluk ve grupların sosyal sorumluluk yaklaşımlarında farklılaşmaya neden olduğu görülmektedir (Choi, 2018, s.932; Fidan ve Şentürk, 2017, s.62). Bu varsayımdan hareketle çalışmanın tali amaçlarından biriside BIST Sürdürülebilirlik Endeksinde yer alan işletmelerin sektörel açıdan kurumsal sosyal sorumluluk çalışmalarında farklılaşmanın ne yönde olduğunun tespit edilmesidir.

\section{Metodoloji}

Kurumsal sosyal sorumluluğun ölçümünde kabul edilen yöntemleri aşağıdaki gibi sıralamak mümkündür (Sarıkaya ve Akarca, 2011):

- İçerik Analizi

- İtibar Endeksi

- KLD Endeksi

- Zehirli Atık Endeksi

İçerik analizi yöntemi elde edilen verileri tanımlamaya, gruplamaya ve bu işlemler sonucu elde edilen çıtıları yorumlayarak objektif sonuçlara ulaşılmasını amaçlamaktadır (Yıldırım ve Şimşek, 2016, s.242).

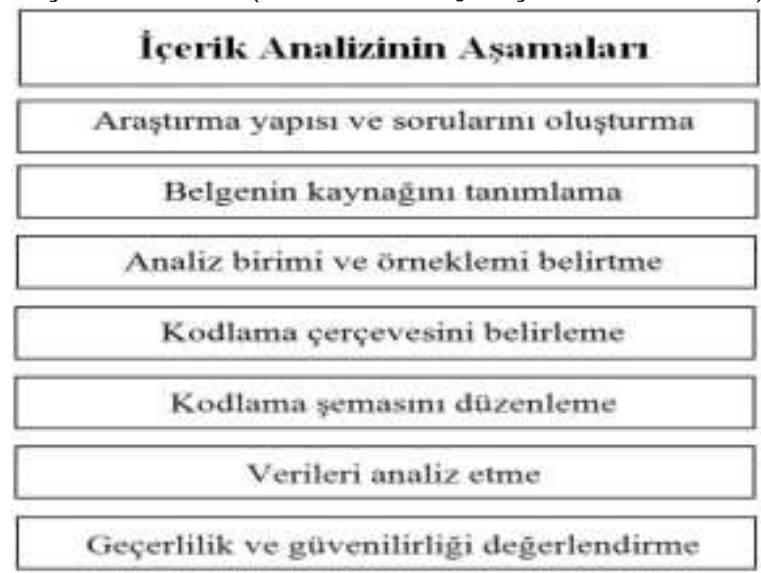

Şekil 1. İçerik Analizinin Aşamalan (Harris, 2001, s.194; Chun, 2019, s. 61'den Uyarlanmıştır) 
Çalışmanın geçerlilik ve güvenilirliğini artırmak için Şekil 1'de ifade edilen içerik analizi süreci takip edilmiştir (Harris, 2001, s.194; Chun, 2019, s.61). Ayrıca çalışma sonuçlarının daha objektif bir zeminde değerlendirilmesi için nitel analiz programlarından faydalanılmıştır.

\section{Araştırma Çerçevesi ve Soruları}

Çalışma örneklemini Kasım 2018 - Ekim 2019 döneminde BİST Sürdürülebilirlik Endeksinde yer alacak şirketler oluşturmaktadır. Bu dönem BİST Sürdürülebilirlik Endeksinin oluşturulması için BİST 50 Endeksi kapsamında yer alan şirketlere ek olarak Sürdürülebilirlik Endeksi'nde yer alan ve değerlemeye alınmak üzere bildirimde bulunan gönüllü şirketlerle birlikte toplam 71 şirket değerleme kapsamına alınmış, bu değerleme çalışması sonucunda endeks seçim kriterlerindeki eşik değerleri geçen aşağıda sıralanan şirketler Kasım 2018 - Ekim 2019 döneminde BIST Sürdürülebilirlik Endeksinde bulunmaktadır.

Çalışmanın amaçları kapsamında BİST Sürdürülebilirlik Endeksi içindeki şirketlerin KSS faaliyetlerinde hangi konulara daha fazla yoğunlaştıkları bu çalışmaların ne yönde geliştikleri ve KSS faaliyetlerinin endeks içinde sektörel açıdan farklılık taşıyıp taşımadığı test edilmektedir.

\section{Belgenin Kaynağını Tanımlama ve Örneklemi Belirtme}

Çalışma kapsamında BİST Sürdürülebilirlik Endeksinde yer alan işletmelerin kurumsal sosyal sorumluluk faaliyetleri sürdürülebilirlik raporları ve şirket web sayfaları üzerinden taranarak, nitel araştırma yöntemlerinden içerik analizine tabi tutulmuştur. Bu kapsamda Tablo 1. içinde yer alan şirketlerin sosyal sorumluluk faaliyetleri taranmıştır. 
Tablo 1. BİST Sürdürülebilirlik Endeksindeki İşletmeler (Kasım 2018 - Ekim 2019) (BIST, 2019).

\begin{tabular}{llllll}
\hline $\mathbf{N o}$ & ŞİRKET & No & ŞİRKET & No & ŞİRKET \\
\hline $\mathbf{1}$ & AK ENERJI & 18 & GARANTI B. & 35 & T.S.K.B. \\
\hline $\mathbf{2}$ & AKBANK & 19 & GLOBAL HOLD. & 36 & TAT GIDA \\
\hline $\mathbf{3}$ & AKSA & 20 & İŞ BANKASI & 37 & TAV \\
\hline $\mathbf{4}$ & AKSA ENERJi & 21 & KOC HOLD. & 38 & TEKFEN HOLD. \\
\hline $\mathbf{5}$ & ANADOLU CAM & 22 & KORDSA TEKSTIL & 39 & TOFAS OTO. \\
\hline $\mathbf{6}$ & ANADOLU EFES & 23 & LOGO YAZILIM & 40 & TÜPRAŞ \\
\hline $\mathbf{7}$ & ANEL ELEKTRIK & 24 & MİGROS TICARET & 41 & THY \\
\hline $\mathbf{8}$ & ARÇELIK & 25 & NETAS TELEKOM & 42 & TÜRK TEL. \\
\hline $\mathbf{9}$ & ASELSAN & 26 & OTOKAR & 43 & TÜRK TRAK. \\
\hline $\mathbf{1 0}$ & AYGAZ & 27 & PEGASUS & 44 & TURKCELL \\
\hline $\mathbf{1 1}$ & BRİSA & 28 & PETKIMM & 45 & ÜLKER BISK. \\
\hline $\mathbf{1 2}$ & CIMSA & 29 & POLISAN HOLD. & 46 & VAKIFLAR B. \\
\hline $\mathbf{1 3}$ & COCA COLA & 30 & SABANCI HOLD. & 47 & VESTEL \\
\hline $\mathbf{1 4}$ & DOĞAN HOLD. & 31 & SEKERBANK & 48 & VESTEL \\
\hline $\mathbf{1 5}$ & DOĞUŞ OTO & 32 & SİSE CAM & 49 & YAPI VE KREDİ \\
\hline $\mathbf{1 6}$ & EREĞLİ DEMİ Ç. & 33 & SODA SANAYİI & 50 & ZORLU ENERJI \\
\hline $\mathbf{1 7}$ & FORD OTOSAN & 34 & HALKBANK & & \\
\hline
\end{tabular}

Tablo 2. BISST Sürdürülebilirlik Endeksinde Yer Alan Şirketlerin Sektör Dağılımları

\begin{tabular}{lll}
\hline SEKTÖRLER & Sektör Kodu & Sektör Üye \\
\hline FINANS & F & 8 \\
\hline METAL EŞYA MAKİNE & MEM & 7 \\
\hline HOLDİNG YATIRIM & HY & 7 \\
\hline KİMYA PETROL PLASTİ & KPP & 6 \\
\hline İMALAT SANAYİ & İS & 5 \\
\hline ENERJİ & EN & 4 \\
\hline GIDA İÇECEK & Gİ & 4 \\
\hline TEKNOLOJI YAZILIM & TY & 3 \\
\hline TİCARET & T & 2 \\
\hline HABERLEŞME & H & 2 \\
\hline ULAŞTIRMA & U & 2 \\
\hline
\end{tabular}

\section{Kodlama Çerçevesini Belirleme}

Tablo 3. kapsamında yer alan faaliyet türü boyutları belirlenirken, BİST Sürdürülebilirlik Endeksinde yer alan firmaların sürdürülebilirlik raporları referans olarak kabul edilmiştir. Sürdürülebilirlik raporunun düzenlenmesi bir şirketin hissedarları dışındaki paydaşlarına karşıda sorumlu 
olduğunu kabul etmesi anlamını taşımaktadır (BİST, 2014). Günümüzde BİST sürdürülebilirlik endeksinde yer alan şirketlerin kurumsal sosyal sorumluluk faaliyetleri Tablo 3. içinde yer alan boyutlar ve bu boyutların içeriği açısından taranmıştır.

Tablo 3. Kurumsal Sosyal Sorumluluk Faaliyetleri Kodlama Tablosu

\begin{tabular}{|c|c|}
\hline FAALIYYET İÇERIIĞİ KODLAMASI (1) & $\begin{array}{l}\text { KSS FAALIYYET TÜRÜ KOD- } \\
\text { LAMASI (2) }\end{array}$ \\
\hline $\begin{array}{l}\text { (a1)Görsel, İşitsel ve Dramatik Sanatların Gelişimi ve } \\
\text { Desteklenmesine Yönelik Faaliyetler; } \\
\text { (a2)Turizm ve Tarım Gibi Sektörel Alanların Gelişimi ve } \\
\text { Desteklenmesine Yönelik Faaliyetler; } \\
\text { (a3)Çocuk, Aile ve Cinsiyet Eşitliğine Odaklanan Sosyal } \\
\text { Projelerin Desteklenmesine Yönelik Faaliyetler; } \\
\text { (a4)Sosyal ve Kültürel Faaliyetler Kapsamında } \\
\text { Değerlendirilen Burs, Bağış ve Destekler }\end{array}$ & $\begin{array}{l}\text { Sosyal ve Kültürel Faaliyetler } \\
(\mathrm{A})=(\mathrm{a} 1, \mathrm{a} 2, \mathrm{a} 3, \mathrm{a} 4)\end{array}$ \\
\hline $\begin{array}{l}\text { (b1)Ağaçlandırma Faaliyetleri; } \\
\text { (b2)Doğa, Çevre ve Biyoçeşitliliğin Korunması Faaliyetleri, } \\
\text { (b3)Karbon İzi Azaltma Faaliyetleri }\end{array}$ & $\begin{array}{l}\text { Çevresel Faaliyetler }(\mathrm{B})= \\
(\mathrm{b} 1, \mathrm{~b} 2, \mathrm{~b} 3)\end{array}$ \\
\hline $\begin{array}{l}\text { (c1)Öğrencilerin Bilgi ve Yeteneklerinin Gelişmesine Yönelik Eği- } \\
\text { tim Odaklı Faaliyetler; } \\
\text { (c2)Bilimsel Çabaların Desteklenmesine Yönelik Faaliyetler; } \\
\text { (c3)Okuma Alışkanlı̆̆ı ve Kitap Ulaşılabilirliğini } \\
\text { Artırmaya Yönelik Faaliyetler; } \\
\text { (c4)Aile, Öğretmen ve Öğrenci Odaklı Eğitim Faaliyetleri }\end{array}$ & $\begin{array}{l}\text { Eğitim Odaklı Faaliyetler }(\mathrm{C})= \\
(\mathrm{c} 1, \mathrm{c} 2, \mathrm{c} 3, \mathrm{c} 4)\end{array}$ \\
\hline $\begin{array}{l}\text { (d1)Genel Olarak Toplum Sağlığını } \\
\text { İileştirmeyi Amaçlayan Faaliyetler; } \\
\text { (d2)Dezavantajlı Grupların Rehabilite Edilmesine } \\
\text { Yönelik Faaliyetler }\end{array}$ & $\begin{array}{l}\text { Toplum Sağlığ } \text { Faaliyetleri (D) } \\
= \\
(\mathrm{d} 1, \mathrm{~d} 2)\end{array}$ \\
\hline $\begin{array}{l}\text { (e1)Enerji Verimliliğini Artırmaya Yönelik Faaliyetler; } \\
\text { (e2)Temiz Enerji Bilincinin Oluşturulmasına Yönelik } \\
\text { Faaliyetler }\end{array}$ & $\begin{array}{l}\text { Enerji Verimliliği }(E)= \\
(e 1, e 2)\end{array}$ \\
\hline
\end{tabular}

\section{Verilerin Analiz Edilmesi ve Bulgular}

Çalışma kapsamında BİST Sürdürülebilirlik Endeksinde yer alan firmaların kurumsal internet siteleri, sürdürülebilirlik raporları ve ulusal basında yer alan kurumsal sosyal sorumluluk faaliyetleri ayrıntılı bir analizi tabi tutulmuştur. Bu faaliyetler bir şirketin sürekliliğine katkı sunmasını yanı sıra örgüt paydaşları tarafından benimsenmesi ve desteklenmesini sağlamaktadır. Tablo 4.'te Sürdürülebilirlik Endeksinde yer alan firmaların 2017 tarihinden itibaren kurumsal sosyal sorumluluk faaliyetleri kap- 
mında yürütmüş oldukları projeler, vermiş oldukları destekler, yapmış oldukları çalışmaların Tablo 3'te belirlenen boyutlara göre dağılımı yapılmıştır. Bu tarama sürecinde şirketlerin ana faaliyetlerini destekleyici sponsorluk çalışmaları kapsam dişında tutulmuştur. Tablo 3'te yer alan kurumsal sosyal sorumluluk faaliyetleri topluma doğrudan ve faaliyet sonucu herhangi bir çıkar beklenmeden yapılan kurumsal sosyal sorumluluk çalışmalarıdır.

Sürdürülebilirlik endeksinde yer alan şirketlerin kurumsal sosyal sorumluluk faaliyetlerinin genel olarak sosyal ve kültürel faaliyetler kapsamında yoğunlaştığı görülmektedir. Sürdürülebilirlik endeksinde yer alan firmaların (33 Şirket) \%66' sının kurumsal sosyal sorumluluk kapsamında en az bir sosyal ve kültürel faaliyete; (29 Şirket) \% 58'inin en az bir eğitim odaklı kurumsal sosyal sorumluluk çalışmasına imza attığı görülmektedir. Yine bu şirketlerin (14 Şirket) \%28'inin 2017 tarihinden itibaren en az bir çevresel sosyal sorumluluk faaliyeti yürüttüğü görülmektedir.

Tablo 4. BIST Sürdürülebilirlik Endeksi Şirketlerinin Kurumsal Sosyal Sorumluluk Faaliyetleri Tablosu

\begin{tabular}{|c|c|c|c|c|c|c|c|c|c|}
\hline & ŞİRKET & 1 & 2 & 3 & & ŞİRKET & 1 & 2 & 3 \\
\hline 1 & AK ENERJI & (A) & (B) & (E) & 26 & OTOKAR & (A) & & \\
\hline 2 & AKBANK & (A) & (C) & & 27 & PEGASUS & (A) & & \\
\hline 3 & AKSA & (A) & (C) & & 28 & PETKIM & (A) & & \\
\hline 4 & AKSA ENERJİ & (E) & & & 29 & POLISAN HOLD. & (A) & (B) & \\
\hline 5 & ANADOLU CAM & (B) & (C) & & 30 & SABANCI HOLD. & (C) & & \\
\hline 6 & ANADOLU EFES & (A) & & & 31 & SEKERBANK & (A) & (C) & \\
\hline 7 & ANEL ELEKTRIKK & (A) & (B) & & 32 & SİSE CAM & (A) & (B) & (C) \\
\hline 8 & ARÇELIK & (A) & (C) & & 33 & SODA SANAYİI & (B) & & \\
\hline 9 & ASELSAN & (C) & & & 34 & HALKBANK & (A) & (C) & \\
\hline 10 & AYGAZ & (A) & (C) & (D) & 35 & T.S.K.B. & (A) & (C) & \\
\hline 11 & BRISA & (A) & (B) & & 36 & TAT GIDA & (C) & & \\
\hline 12 & CIMSA & (C) & (D) & & 37 & TAV & (C) & (D) & \\
\hline 13 & COCA COLA & (A) & & & 38 & TEKFEN HOLD. & (A) & (D) & \\
\hline 14 & DOĞAN HOLD. & (A) & (B) & (C) & 39 & TOFAS OTO. & (A) & (C) & \\
\hline 15 & DOĞUŞ OTO & (A) & (C) & & 40 & TÜPRAŞ & (C) & & \\
\hline 16 & EREĞLI DEMIR & (A) & (B) & & 41 & THY & (A) & (B) & (C) \\
\hline 17 & FORD OTOSAN & (B) & & & 42 & TÜRK TELEKOM & (C) & (D) & \\
\hline 18 & GARANTİ B. & (C) & & & 43 & TÜRK TRAKTOR & (A) & & \\
\hline 19 & GLOBAL HOLD. & (A) & (C) & & 44 & TURKCELL & (C) & & \\
\hline 20 & İ̧̧ BANKASİ & (C) & & & 45 & ÜLKER BİSKUVİ & (C) & & \\
\hline 21 & KOC HOLD. & (A) & & & 46 & VAKIFLAR B. & (A) & (B) & (C) \\
\hline 22 & KORDSA TEKST. & (C) & & & 47 & VESTEL ELKTR. & (A) & & \\
\hline 23 & LOGO YAZILIM & (A) & (B) & & 48 & VESTEL BEYAZ & (A) & & \\
\hline 24 & MİGROS TİC. & (A) & (B) & (C) & 49 & YAPI VE KREDİ & (A) & (C) & \\
\hline
\end{tabular}




\begin{tabular}{llllllll}
\hline $\mathbf{2 5}$ & NETAS TEL. & (B) & $\mathbf{5 0}$ & ZORLU ENERJI & (A) & (C) & (E) \\
\hline
\end{tabular}

BİST sürdürülebilirlik endeksinde bulunan işletmelerin kurumsal sosyal sorumluluk çalışmaları kapsamında sosyal ve kültürel faaliyetler, eğitim faaliyetleri ve çevre faaliyetleri dışında düşük yoğunlukta enerji verimliliği ve toplum sağlığı gibi konularda kurumsal sosyal sorumluluk çalışmaları yaptıkları tespit edilmiştir. Ancak bu çalışmalar düşük yoğunlukta olduğu için tablo içinde yer bulamamıştır.

Yürütülen çalışma kapsamında kurumsal sosyal sorumluluk açısından sosyal ve kültürel faaliyetler kapsamında en çok sergi, konser, festival, bilgilendirme etkinlik ve toplantıları; bağış ve destekler; vakıflarla yürütülen işbirlikleri yer almaktadır.

Kurumsal sosyal sorumluluk açısından eğitim faaliyetleri kapsamında en çok kariyer programları, eğitim ve burs destekleri; üniversite, vakıf ve derneklerle yürütülen öğrenci yetkinliklerinin geliştirilmesine yönelik faaliyetler bulunmaktadır. Kurumsal sosyal sorumluluk açısından çevresel faaliyetler kapsamında en çok fidan dikme, ağaçlandırma ve orman geliştirme projelerinin yer aldığı; çevre kirliliğinin önlenmesi, biyoçeşitlilik ve doğa hayvanlarının korunmasına yönelik faaliyetlere yer verildiği görülmektedir.

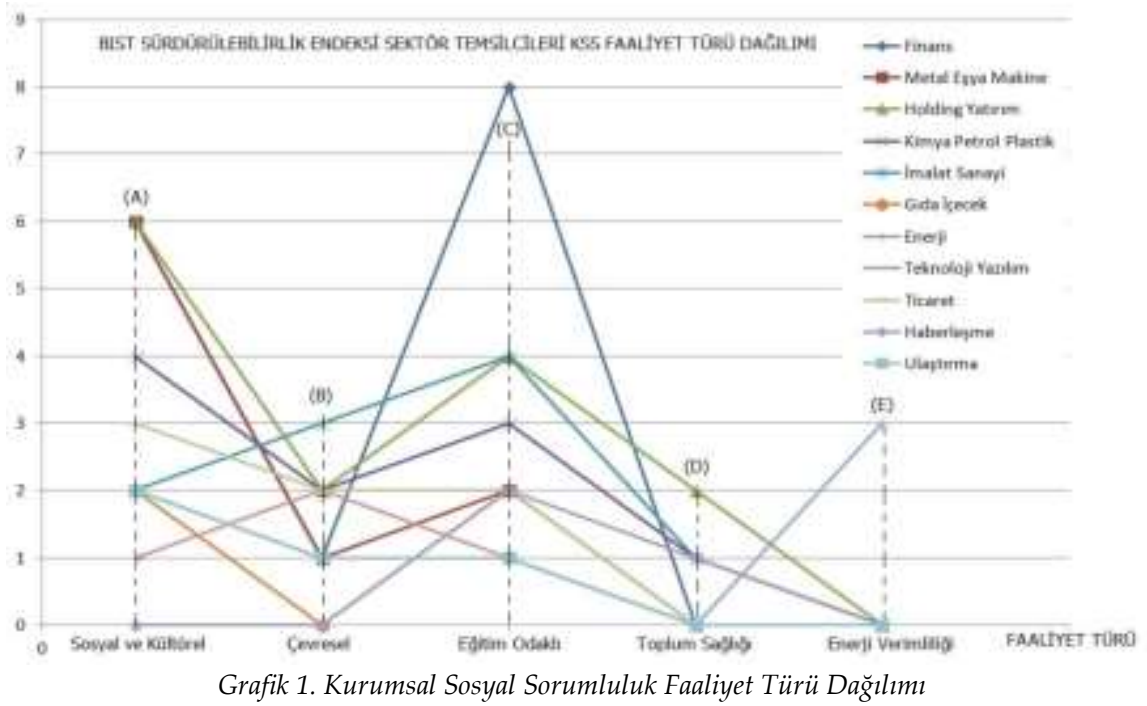


BİST Sürdürülebilirlik Endeksinde yer alan işletmelerin kurumsal sosyal sorumluluk faaliyetleri sektör açısından değerlendirildiğinde anlamlı farklılıkların bulunduğu görülmektedir. Sektörel değerlendirme sonucunda faaliyet türü açısından finans (F) ve imalat sektörü (İS) temsilcilerinin eğitim odaklı çalışmalara; metal eşya makine (MEM), holding $(\mathrm{H})$, kimya petrol plastik (KPP), ticaret $(\mathrm{T})$ ve ulaştırma (U) sektörü temsilcilerinin sosyal ve kültürel faaliyetlere yönelik çalışmalara yoğunlaştığ tespit edilmiştir. Enerji (E) sektörü temsilcisi şirketlerin diğer şirketlerden belirgin bir yaklaşım farklılığıyla enerji verimliliğine yönelik kurumsal sosyal sorumluluk çalışmalarına yoğunlaştığı görülmektedir. Toplum sağlığına yönelik KSS faaliyetlerinin sadece haberleşme $(\mathrm{H})$ sektörü temcileri tarafından yapıldığı görülmektedir.

Çalışmanın amaçları kapsamında BİST Sürdürülebilirlik Endeksi içindeki şirketlerin KSS faaliyetleri üzerine genel bir değerlendirme yapıld1ğında öncelik sıralamasına göre;

- $\quad$ Sosyal ve kültürel faaliyetlere $\sum(\mathrm{A})=(\mathrm{a} 1, \mathrm{a} 2, \mathrm{a} 3, \mathrm{a} 4)=33$

- Eğitim odaklı faaliyetlere $\sum(\mathrm{C})=(\mathrm{c} 1, \mathrm{c} 2, \mathrm{c} 3, \mathrm{c} 4)=30$

- Çevresel faaliyetlere $\sum(\mathrm{B})=(\mathrm{b} 1, \mathrm{~b} 2, \mathrm{~b} 3)=15$

- Toplum sağlığ 1 faaliyetlerine $\sum(\mathrm{D})=(\mathrm{d} 1, \mathrm{~d} 2)=5$

- $\quad$ Enerji verimliliğine yönelik $\sum(\mathrm{E})=(\mathrm{e} 1, \mathrm{e} 2)=3$

faaliyetlere yoğunlaştığ görülmektedir.

BİST Sürdürülebilirlik Endeksi içindeki şirketlerin KSS faaliyetleri eğilimlerinin endeks içinde sektör grupları açısından farklılık taşıdığı görülmektedir (Grafik 1).

\section{Sonuç}

Yirmi birinci yüzyılın rekabet ortamında örgütlerin sürekliliği sadece asli faaliyetlerin yerine getirilmesine bağlı bulunmamaktadır. Örgütler iç ve dış paydaşlarının beklentilerini en yüksek düzeyde karşılamak durumundadır. Dolayısıyla örgütlerin ifade ettiği taahhütleri ve geleceğe yönelik stratejik yönlendirme araçları süreklilik açısından hayati önem arz etmektedir. Günümüzde örgütlerin kurumsal sosyal sorumluluk uygulamaları ve anlayışları örgüt kültürü ve bağlılığını artırma potansiyeline sahiptir (Elmas Atay ve Tüzüner, 2018, s.272). 
Çalışma sonucunda elde edilen bulgulardan BİST Sürdürülebilirlik Endeksinde yer alan firmaların hangi kurumsal sosyal sorumluluk boyutuna daha fazla önem verdikleri tespit edilmiştir. BİST sürdürülebilirlik endeksinde bulunan işletmelerin kurumsal sosyal sorumluluk çalışmaları kapsamında en yoğun olarak sosyal ve kültürel faaliyetler boyutuna yönelik proje ve etkinliklerinin bulunduğu tespit edilmiştir. Bununla birlikte kurumsal yönetim açısından Türkiye'nin en gözde şirketlerinin sosyal sorumluluk kapsamında çevresel duyarlılık ve eğitim odaklı faaliyetlere yöneldiği gözlemlenmiştir. Bu kapsamda incelenen şirketlerin yüksek çevre duyarlılığı kapsamında özellikle ağaçlandırma çalışmaları üzerinde ciddi faaliyetlerinin olduğu tespit edilmiştir. Yine BİST Sürdürülebilirlik Endeksinde yer alan şirketlerin vakıf ve üniversitelerle yakın işbirliği içinde bulunduğu; okul, eğitim ve bilim odaklı projelere daha fazla önem verdikleri tespit edilmiştir. Endeks içinde yer alan enerji sektörü temsilcileri dışında enerji verimliliği konusu üzerinde KSS çalışması bulunan şirket bulunmamaktadır. Sektörel açıdan kurumsal sosyal sorumluluk çalışma eğilimlerinde farklılık bulunmaktadır. Sürdürülebilirlik endeksi içinde yer alan şirketlerin KSS faaliyetleri eşbiçimsel bir özellik taşımamaktadır.

Sürdürülebilirlik Endeksinde yer alan bu firmaların sürdürülebilirlik raporlarında, basında ve literatürde üzerinde önemle durulan enerji ve toplum sağlığ boyutlarının somut projelerle yeterince desteklenmediği görülmektedir. Bu alanlara yönelik farkındalık oluşturma, proje geliştirme, izleme ve sonuçlandırma aşamalarının daha fazla zaman, emek ve sermaye gerektirmesi başlıca kısıtlar arasında yer almaktadır. 


\title{
EXTENDED ABSTRACT
}

\section{A Content Analysis on Corporate Social Responsibility Activities of Companies in BIST Sustainability Index}

\author{
Oğuzhan Aytar
}

Karamanoğlu Mehmetbey University

Businesses interact with different stakeholders in the environment in which they work. Each of these stakeholder groups has a number of expectations from businesses. In this context, it can be seen that corporate social responsibility activities contribute positively to the common expectations and satisfaction levels of the stakeholders. The universal qualities of the corporate social responsibility approach have different managerial effects on different cultures (Paşamehmetoğlu ve Gökoğlu, 2019, s.126). For example, there are differences in semantic perception of corporate social responsibility among US, EU and Chinese firms; also significant differences in CSR communication between Asian, European, US \Canadian and Chinese companies (Liao vd., 2018, s.362; Liao vd., 2017, s.334-335; Benn ve Bolton, 2011, s.59). According to some international research results, there are significant regional differences in companies' perception of CSR and communication of CSR (Liao vd., 2018; Liao vd., 2017).

The formulation of corporate social responsibility is an issue that emerged after The World War II. Corporate social responsibility means that companies with the ability to regulate themselves should be transparent and ethical by taking into account all stakeholders in the process of producing goods and services (Elmualim, 2017, s.1578; Suher, 2010, s.34). An organization with a sense of social responsibility and sensitive to the society which is developing a strong social capital. This feature brings awareness to the organization and makes it more preferred (Sarıkaya ve Akarca, 2011, s.61). Corporate social responsibility activities of companies with high level of corporate sustainability performance are considered as 
a guide. Therefore, the content of corporate social responsibility activities of companies and to see how the differences develop is important in terms of sectoral differences. BIST Sustainability Index measures the level of giving importance to sustainable policies for the solution of social and environmental problems.

The methods adopted in the measurement of corporate social responsibility can be listed as follows: Content Analysis, Reputation Index, KLD Index end Toxic Waste Index (Sarkaya ve Akarca, 2011). The aim of this study is to analyze the corporate social responsibility activities of the companies in the BIST Sustainability Index and to analyze the content within the scope of the predefined themes. From this point it is important that social responsibility activities of the organizations included in the BIST Sustainability Index. Qualitative research is a way of producing knowledge that the researcher shapes with his/her own efforts and develops in order to explore the basis and structure of social systems Content analysis method, one of the qualitative research methods, was used in the study. The content analysis method aims to achieve objective results with defining, grouping and interpreting the obtained data as a result of these operations. In order to increase the validity and reliability of the study, the content analysis process, which is listed as identify research questions and constructs, identify the source of document, specify sampling and the unit of analysis, identify the coding framework, devise the coding scheme, analyze the data, assess validity and reliability steps was followed (Harris, 2001, s.194; Chun, 2019, s.61).

Within the scope of the objectives of the study, the subjects in which the companies within the BIST Sustainability Index concentrate more on CSR activities are tested, the direction of these studies developed and whether CSR activities differ in terms of the sector. Corporate social responsibility activities of the companies included in the sustainability index are concentrated in the scope of social and cultural activities. In terms of corporate social responsibility, most of the social and cultural activities are included such as exhibitions, concerts, festivals, information events and meetings; donations and supports; cooperation with foundations. In terms of corporate social responsibility there are activities to improve student competencies carried out with universities, foundations and associations, most of the training activities are career programs, training and 
scholarship supports. In terms of corporate social responsibility, environmental activities mostly include sapling, afforestation and forest development projects; activities for the prevention of environmental pollution, biodiversity and protection of natural animals.

When the corporate social responsibility activities of the companies included in the BIST Sustainability Index are evaluated in terms of the sector, it is seen that there are significant differences. As a result of sectoral evaluation, it is seen that, representatives of finance (F) and manufacturing sectors (MS) are concentrated on education-oriented studies; the representatives of metal goods machinery (MGM), holding $(\mathrm{H})$, chemical petroleum plastic (CPP), trade (T) and transportation (TRS) sectors are concentrated on social and cultural activities in terms of activity type. It is seen that the companies representing the energy (E) sector are concentrating their efforts on efficiency with a distinctive approach difference from other companies in terms of corporate social responsibility. It is seen that, only representatives of communication (C) sector are concentrated on CSR activities for public health. As a result of the study, it was determined which corporate social responsibility dimension is important for the companies in BIST Sustainability Index. It was determined that the projects and activities related to the social and cultural activities dimension were the most intense field in terms of corporate social responsibility studies of the companies in the BIST sustainability index. However, it has been observed that Turkey's most popular companies tend to focus on social responsibility activities related to education and environmental awareness in terms of corporate management.

It has been determined that the examined companies have serious activities especially on afforestation works with high environmental sensitivity. It is also stated that the companies in the BIST Sustainability Index cooperate closely with foundations and universities; they attach more importance science-oriented projects together with schools and students. It is seen that the energy and public health dimensions emphasized in the press, sustainability reports and literature, are not adequately supported with concrete projects by these companies in the Sustainability Index. For these fields awareness, project development, monitoring and finalization require more time, effort and capital are the main constraints. In the results of the study, it was found that the CSR activities tendency differed in 
terms of sector groups of the companies in the Sustainability Index. The Corporate Social Responsibility activities of the companies in the Sustainability Index are not isomorphic.

\section{Kaynakça / References}

Argüden, Y. (2007). Kurumsal sosyal sorumluluk. (C. C. Aktan Ed.) Kurumsal Sosyal Sorumluluk, Isşletmeler ve Sosyal Sorumluluk, içinde (s.25-30). İstanbul: İGİAD Yayını.

Benn, S. ve Bolton, D. (2011). Key concepts in corporate social responsibility, London: Sage Publications Ltd.

BİST (2014). Şirketler için sürdürülebilirlik rehberi, Ekim, 15 Şubat 2019 tarihinde https://www.borsaistanbul.com/data/kilavuzlar/surdurulebilirlik-rehberi.pdf adresinden ulaşılmıştır.

BİST (2019). BİST sürdürülebilirlik endeksi 1 Kasım 2018 tarihinden itibaren geçerli dönemsel değişiklikler, 25 Şubat 2019 tarihinde http://www.borsaistanbul.com/duyurular/2018/10/26/bist-surdurulebilirlik-endeksi-kas\%C4\%B1m-2018-ekim-2019-donemi-sirketleri-belli-oldu adresinden ulaşılmıştır.

Boz, D., Duran, C. ve Yurt, S. (2019). Kurumsal sosyal sorumluk ve kurumsal yönetim arasındaki etkileşimin veri zarflama ile analizi: BİST kurumsal yönetim endeksindeki firmalar üzerinde bir uygulama, Journal of Yasar University, 14 (54), 119-126.

Can, E. ve Özgül, B. (2018). Türk İhracat şirketleri sürdürülebilirlik ifadeleri üzerine bir içerik analizi, Istanbul Management Journal, 29 (84) ,7-30

Carroll, A., B. (1991). The pyramid of corporate social responsibility: Toward the moral management of organizational stakeholders, Business Horizons, 34 (4), 39-48.

Cheung, Y. L., Tan, W. ve Wang, W. (2018). National stakeholder orientation, corporate social responsibility, and bank loan cost. Journal of Business Ethics, 150 (2), 505-524.

Choi, J. J., Jo, H., Kim, J. ve Kim, M. S. (2018). Business groups and corporate social responsibility. Journal of Business Ethics, 153(4), 931-954. 
Çelik, A. (2007). Şirketlerin sosyal sorumlulukları. (C. C. Aktan Ed.), Kurumsal Sosyal Sorumluluk, Işletmeler ve Sosyal Sorumluluk, içinde (s.42-57.) İstanbul: İGİAD Yayını

Elmas, A. S. ve Tüzüner, V. L. (2018). Kurumsal sosyal sorumluluk ve insan kaynakları uygulamaları birbirlerini destekliyor mu? Bankaların web sitelerinin içerik analizi ile değerlendirilmesi, Pamukkale Üniversitesi Sosyal Bilimler Enstitüsü Dergisi, 32, 271-285.

Elmualim, A. (2017). CSR and sustainability in FM: evolving practices and an integrated index. Procedia Engineering, 180, 1577-1584.

Fidan, Z. ve Şentürk, Z. A. (2017). Kurumsal sosyal sorumluluk (KSS) Çalışmalarında işbirliği: Akbank, Garanti Bankası ve Türkiye İş Bankası üzerine bir değerlendirme. Selçuk Üniversitesi İletişim Fakültesi Akademik Dergisi, 9 (4), 40-65.

Golob, U., Turkel, S., Kronegger, L. ve Uzunoglu, E. (2018). Uncovering CSR meaning networks: A cross-national comparison of Turkey and Slovenia. Public Relations Review, 44 (4), 433-443.

Gör, Y. ve Tekin, B. (2018). Kurumsal sosyal sorumluluk kavramının karlılık ile ilişkisi üzerine bir çalışma: Bist 100 örneği, Sosyal Araştırmalar ve Davranış Bilimleri Dergisi, 4 (5), 18-30.

Karadeniz, E. ve Ünlübulduk, S., N. (2018). dünyada marka değeri en yüksek havayolu işletmeleri ile Borsa İstanbul Havayolu İşletmelerinde kurumsal sosyal sorumluluk faaliyetlerinin analizi, Seyahat ve Otel İsletmeciliği Dergisi, 15 (2), 370-385.

Kunz, M. B. (2018). Corporate social responsibility reporting on fortune 500 corporate websites: Review and analysis. International Journal of Business \& Public Administration, 15 (1), 30-51.

Liao, P. C., Liao, J. Q., Wu, G., Wu, C. L., Zhang, X. L., ve Ma, M. C. (2018). Comparing international contractors' CSR communication patterns: A semantic analysis. Journal of cleaner production, 203, 353366.

Liao, P. C., Xia, N. N., Wu, C. L., Zhang, X. L. ve Yeh, J. L. (2017). Communicating the corporate social responsibility (CSR) of international contractors: Content analysis of CSR reporting. Journal of Cleaner Production, 156, 327-336. 
Önder, Ş. (2019). İşletmelerin kurumsal sosyal sorumlulukları ve finansal performansı arasındaki ilişkinin çift yönlü incelenmesi. Muhasebe ve Vergi Uygulamalar Dergisi, 12(2), 181-196.

Özkan, A., Tanç, Ş. G. ve Taşdemir, B. (2018). Sürdürülebilirlik açıklamaları kapsamında kurumsal sosyal sorumluluğun kârlılık üzerine etkisi: BİST sürdürülebilirlik endeksinde bir araştırma. World of Accounting Science, 20 (3), 560-577.

Paşamehmetoğlu, A. ve Gökoğlu, M., M. (2019). Kurumsal sosyal sorumluluk anlayışının türkiye'deki yönetsel uygulamaları: İstanbul zincir otelleri üzerine bir araştırma. Akdeniz İIBF Dergisi, 19 (1), 106132.

Sarıkaya, M. ve Akarca, Y. (2011). Kurumsal sosyal sorumluluk ölçüm teknikleri. Denetişim Dergisi, 8, 60-67.

Yıldırım, A. ve Şimşek, H. (2016). Sosyal bilimlerde nitel araştırma yöntemleri, Ankara: Seçkin Yayıncılık.

\section{Kaynakça Bilgisi / Citation Information}

Aytar, O. (2019). BİST sürdürülebilirlik endeksinde yer alan şirketlerin kurumsal sosyal sorumluluk faaliyetleri üzerine bir içerik analizi. OPUS-Uluslararası Toplum Araştırmaları Dergisi, 12(18. UİK Özel say1s1), 320-340. DOI: 10.26466/opus.583811. 